\title{
Comparative Effect of Calcium Phosphate Biocomposite Materials on the Healing of Experimental Defect of Compact Bone Tissue
}

\author{
Oleksii Korenkov ${ }^{1}$ \\ ${ }^{1}$ Department of Morphology, Sumy State University, Sumy, Ukraine \\ J Morphol Sci 2019;36:162-168.
}

Address for correspondence Oleksii Korenkov, MD, Department of Morphology of Sumy State University, 2, Rymskogo-Korsakova st., Sumy, Ukraine 40007 (e-mail: o.koren’kov@med.sumdu.edu.ua).

\begin{abstract}
Keywords

- rats

- reparative osteogenesis

- $\beta$-tricalcium phosphate

- hydroxyapatite

- collagen

Introduction For the treatment of bone defects, a considerably large number of biocomposite calcium-phosphate materials has been developed and used. However, in the scientific literature, there is no information about the comparative effect of biocomposite materials based on $\beta$-tricalcium phosphate, hydroxyapatite, and collagen on the dynamics of healing of the defect of compact bone tissue.

Materials and Methods The experiment was performed on 48 white Wistar rats. In the middle third of the femoral shaft, a perforated defect $2.5 \mathrm{~mm}$ in diameter was reproduced in the bone marrow canal, which was filled with the calcium phosphate material Collapan (Intermedapatit, Moscow, Russia) (hydroxyapatite/collagen/antibiotics) in the animals of the first group, and with Guidor easy-graft Crystal (Sunstar S.A., Etoy, Switzerland) (hydroxyapatite/ $\beta$-tricalcium phosphate) in the animals of the second group. Fragments of the injured bones were examined on the $15^{\text {th }}$ and $30^{\text {th }}$ days by light microscopy with morphometry and scanning electron microscopy. Results It was found that, in the area of implantation of Collapan and of Guidor easygraft Crystal, signs of inflammation were not detected, and osteogenic cells exhibited high topism to biocomposite materials. The biomaterials during the entire period of the experiment are subjected to resorption and replacement by the bone tissue of the regenerate. On the $15^{\text {th }}$ and $30^{\text {th }}$ days of the experiment, the predominance in the rate of biomaterial resorption (of $35.04 \%$ and $53.47 \%$, respectively) and the formation of regenerate bone tissue (of $58.67 \%$ and $50.47 \%$, respectively) was in the area of implantation of Collapan.

Conclusion The biocomposite materials tested exhibit a high biocompatibility, osteoconductive properties, and good integration with the tissues of the regenerate. However, the biocomposite material Collapan undergoes resorption and replacement by the bone tissue of the regenerate much faster, and Guidor easy-graft Crystal provides stability of the defect volume of compact bone tissue due to full resorption and good integration with the tissues of the regenerate.
\end{abstract}

\section{Introduction}

One of the actual and at the same time not completely solved problems of modern traumatology is the treatment of bone defects. Presently, to eliminate this problem, a large number of biocomposite calcium-phosphate materials has been developed and used, which resemble bone tissue by their chemical structure. ${ }^{1}$ One of the most famous components of received

September 24, 2018

accepted

March 28, 2019
DOI https://doi.org/

10.1055/s-0039-1688836. ISSN 2177-0298.
Copyright (e 2019 by Thieme Revinter

Publicações Ltda, Rio de Janeiro, Brazil
License terms

c) $(\oplus) \$$ 
these materials is hydroxyapatite, which was declared by Professor S. Kaufman in 1997 at the international Congress of Implantology in Germany as "the best medical material of all time." 2 To create biocomposite drugs, hydroxyapatite is often combined with $\beta$-tricalcium phosphate, or with organic natural and synthetic polymers (collagen, polycaprolactone, etc.). Due to this, biocomposite materials acquire properties that were not present in its individual components. It is known that $\beta$-tricalcium phosphate undergoes resorption faster than hydroxyapatite; therefore, due to changes in their ratio in one biocomposite drug, it became possible to regulate the process of resorption of calcium phosphate material in the area of implantation. ${ }^{3-7}$ At the same time, it was found that this biocomposite material undergoes partial resorption and, primarily due to the $\beta$-tricalcium phosphate and hydroxyapatite, remains at the site of the defect for a longer period, ensuring the prevention of atrophy and the preservation of the volume of the bone tissue. ${ }^{8,9}$ With the help of biocomposite materials, in which hydroxyapatite is combined with collagen, there appears an opportunity to fill the deficiency not only of mineral but also organic components of the bone in the bone defect. ${ }^{1}$

There are also numerous publications about biocomposite calcium phosphate materials that prove their safety, biocompatibility, inertness to biological tissues, the ability to osseointegration and gradual biodegradation, to produce osteoconductive influence on the reparative osteogenesis, and to positively influence the restoration of the structure of the injured bone. ${ }^{10-17}$ However, despite this, among the variety of biocomposite materials, it is difficult to identify the best one, so professionals need to focus on their basic properties, advantages, and disadvantages, in order to make the right choice in a particular clinical situation. One of the important criteria of this choice is the dynamics of the rate of biodegradation of the calcium phosphate material and its replacement by the specific structures of the regenerate. However, this information for some commercial biocomposite drugs (based on hydroxyapatite , $\beta$-tricalcium phosphate, and collagen) is completely absent, and for others it is obtained in experiments on the bones of the skull and on trabecular bones. ${ }^{4,5,7,16,18,19}$ At the same time, we did not find any information on studies of the comparative effect of different biocomposite materials on the dynamics of healing of a defect of compact bone tissue in the scientific literature. In addition, in the morphological studies of the regenerative process of the bone after implantation into its defect of biocomposite materials based on $\beta$-tricalcium phosphate, hydroxyapatite, and collagen, the electron microscopic characteristics of the bone regenerate are absent.

We would also like to note that the dynamics of biodegradation of biomaterials and their replacement by tissuespecific regenerate structures can be influenced by many factors, such as the size of the defect, bone regeneration potential, and characteristics of the osteoplastic material (manufacturer, composition, geometric shape, total porosity, pore size, design, size, etc. .) ${ }^{1}$ All this suggests that, for a more predictable effect of biocomposite materials on the dynamics of the healing of bone defects, their pilot models are required.
On the latter, in standard conditions and with the help of various research methods, it is possible to study and compare with each other osteoplastic materials, which optimize reparative osteogenesis. Therefore, the aim of our work was to compare the effect of biocomposite calcium phosphate materials that differ in composition, origin, manufacturer, and microscopic structure on the healing process of the experimental defect of compact bone tissue.

\section{Material and Methods}

The experiment was performed on 48 8-month-old white Wistar rats with the weight of $250 \pm 10 \mathrm{~g}$. All of the procedures were agreed with the Commission on Biomedical Ethics of the Sumy State University, Sumy, Ukraine (minutes number $1 / 1$ of 24.01 .2018 ). The study protocol was done according to the provisions "European Community Directive of 24 November 1986 on the maintenance and use of laboratory animals for research purposes." Before the surgery, the animals were initially injected with $2.5 \mathrm{mg} / \mathrm{kg}$ of intramuscular acepromazine and, 5 minutes later, with 75 $\mathrm{mg} / \mathrm{kg}$ of intramuscular ketamine (Calypsol; Gedeon Richter, Budapest, Hungary). After the induction of anesthesia in the animals, a defect of the medullary canal with a diameter of $2.5 \mathrm{~mm}$ was reproduced under aseptic conditions in the middle third of the femoral diaphysis using a portable drill (Korund-NX, VIOLA, Kiev, Ukraine) with a spherical cutter at low speed with cooling. Then, the experimental animals were divided into 2 groups:

Group 1 (24 rats) - the defect was filled with the biomaterial Collapan (Intermedapatit, Moscow, Russia; registration number 2011/10304 FES) (-Fig. 1), which is an artificial granular biocomposite material consisting of nanostructured hydroxyapatite, of collagen type I from the skin of cattle, and of antibiotics (gentamicin). ${ }^{16}$

Group 2(24 rats) - the defect was filled with the biomaterial Guidor easy-graft Crystal (Sunstar S.A., Etoy, Switzerland; registration number 2008/03310 FES). The preparation is produced in the syringe with granules and a vial with the organic solvent BioLinker (Sunstar S.A., Etoy, Switzerland). The

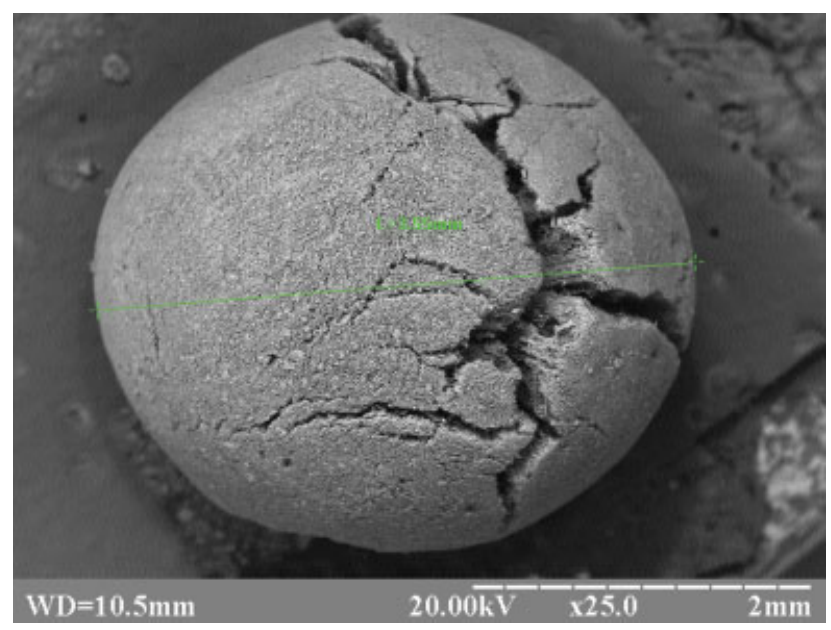

Fig. 1 Granule of the osteoplastic material Collapan $(3.55 \mathrm{~mm})$. Electronic scanning image. 25x magnification. 


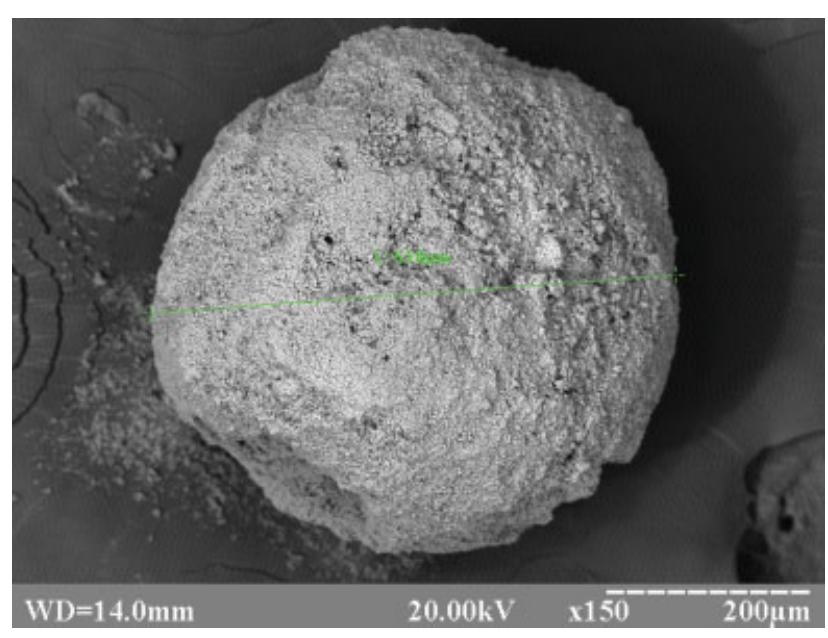

Fig. 2 Granule of the osteoplastic material Guidor easy-graft Crystal $(518 \mu \mathrm{m})$. Electronic scanning image. 150x magnification.

granules consist of $40 \% \beta$-tricalcium phosphate and $60 \%$ hydroxyapatite, and BioLinker, which consists of water and $\mathrm{N}$-methyl-2-pyrrolidone (NMP). Each granule of the material (-Fig. 2 ) is covered with a thin $(10 \mu \mathrm{m})$ polymer of polylactic and polyglycolic acid (PLGA), which is capable of resorption. ${ }^{4,17}$

Before the injection of the material into the defect, the granules were soaked in the BioLinker liquid, which temporarily softened the outer shell of the granules and provided their bonding. In this case, the material gained a lamellar mass consistency, which was easy to model in the shape of the defect. After injecting the material into the bone defect, it was soaked with blood, which ensured the removal of BioLinker, and the material began to harden within minutes. Thus, a stable porous mass with microcells inside the granules with a size ranging from 1 to $10 \mu \mathrm{m}$ and with macrocells between the separate granules was formed.

After implanting into the bone defect of biocomposite materials, the wound was tightly stitched with silk thread through all of the layers of the soft cover, the seam was treated with $3 \%$ alcohol solution of iodine. Then, during the next 3 days after the operation, for the prevention of septic complications, the postoperative seam was treated with an alcohol solution of iodine, and ketorolac (JSC Synthesis, Kurgan, Russia) was injected intramuscularly at a dose of $0.6 \mathrm{mg} 2$ times a day for analgesia.

Next, on the $15^{\text {th }}$ and $30^{\text {th }}$ days after the surgery, the animals were sacrificed by decapitation under deep ether anesthesia, followed by a study of the injured bones using light microscopy with morphometry and scanning electron microscopy.

For light microscopy, we extracted the fragments of the femoral bones from the site of implantation of the osteoplastic material and fixed them in $10 \%$ solution of neutral formalin. After washing with water, the bone samples were subjected to decalcification in $5 \%$ aqueous solution of Trilon $B$ (thylenediaminetetraacetic acid) (BASF, Ludwigshagen, Germany), dehydrated in alcohols of increasing concentration and poured into paraffin. Histological sections were made with a Sannomiya
Reichert microtome (Reichert 820H HistoSTAT Microtome, Austin, Texas, United States), stained with hematoxylin and eosin, analyzed at an Olympus light microscope (Olympus BH2 Microscope, Tokyo, Japan) and photographed with a digital camera (Canon EOS-300D, Tokyo, Japan). ${ }^{20}$

Morphometry of the obtained digital microphotographs was performed using a computer program Video Test Size 5.0 (Video Test-Size 5.0, LLC Microscope Service, St. Petersburg, Russia). With the help of the latter, the area occupied by bone, connective tissue of the regenerate and fragments of biocomposite materials in the site of injury was measured.

For scanning electron microscopy, we extracted the fragments of the femur from the implanted osteoplastic material and placed the samples in a glutaraldehyde holder. In one day, the samples were washed in phosphate buffer, fixed in $1 \%$ osmium tetroxide (OsO4) solution and dehydrated in ethanol of increasing concentrations. Then, the bone fragments were glued on metal tables with electricity conductive adhesive, sprayed with carbon dust in standard vacuum installation of VUP-5 type and examined with a SEM 106-I electron microscope (Selmi, Sumy, Ukraine).

Using light and scanning electron microscopy, we established the morphological characteristics of the newly formed tissue-specific structures of the regenerate, and the nature of their interaction with the osteoplastic materials Collapan and Guidor easy-graft Crystal. Using these methods, we also investigated the state of the structure of the adjacent to the place of implantation maternal bone. ${ }^{21}$ The resulting digital values were treated statistically by calculating the arithmetic mean (M) and its standard error (SE). The significance of differences between the indicators of the animals of the $1^{\text {st }}$ and $2^{\text {nd }}$ groups, at the $15^{\text {th }}$ and the $30^{\text {th }}$ days, was evaluated using the Student-t test with the use of the statistical software Microsoft Excel XP (Microsoft, Redmond, WA, USA). The differences were considered significant at $p<0.05$.

\section{Results}

On the $15^{\text {th }}$ day of the experiment in animals of the $1^{\text {st }}$ and $2^{\text {nd }}$ groups, the defect was filled with bone and connective tissues of the regenerate, which were formed directly on the surface of the biocomposite materials Collapan and Guidor easy-graft Crystal. In this case, bone tissue was located mainly in the peripheral, and connective tissue in the central part of the defect. The connective tissue included fibroblasts, collagen fibers, vessels and fragments of implanted materials. On the outer surface and inside the Collapan and Guidor easy-graft Crystal, appeared osteogenic cells that formed foci of fibrogenesis and osteogenesis. The newly formed tissuespecific structures of the regenerate divided the Collapan granules into separate small fragments and integrated them into their structures. However, in the animals of the $2^{\text {nd }}$ group, there were not only small fragments, but in the vast majority there were large granules of Guidor easy-graft Crystal of rounded shape, which were also integrated into the bone and into the connective tissue of the regenerate. In addition, there were places in which there were layers of connective tissue between the fragments of the implanted 


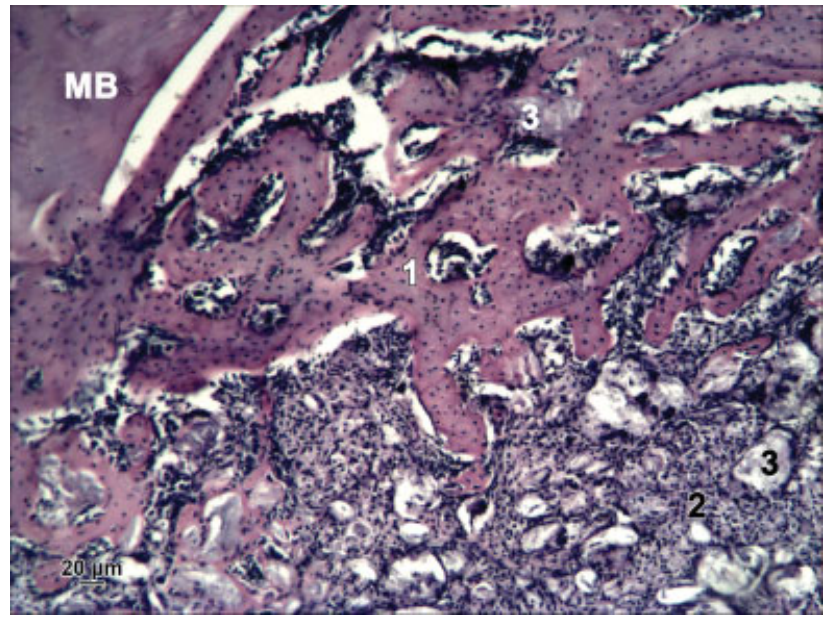

Fig. 3 The area of the femoral defect of the rat on the $15^{\text {th }}$ day after the implantation of Collapan (hematoxylin and eosin). Near the edges of the maternal bone (MB), there is a reticular fibrous bone tissue (1), and at a distance from it, there is mainly connective tissue (2), in the structures of which there are particles of the implanted material (3). bar $=20 \mu \mathrm{m}$

materials and the bone tissue of the regenerate, as well as areas of direct contact of bone tissue with biocomposite materials (-Fig. 3 ).

The bone tissue of the regenerate at the site of implantation of Collapan and Guidor easy-graft Crystal was presented by bone ravine, which formed small- and large-loopy net structures. The latter in animals of the $1^{\text {st }}$ group occupied $55.46 \pm 2.56 \%$ of the entire defect area, and $22.92 \pm 1.67 \%$ in animals of the second group $(p<0.05)$. In addition, in animals of both groups, the bone tissue of the regenerate contained in its composition a significant number of primary osteoblasts, of osteocytes, and integrated small fragments of implanted materials. Primary osteoblasts and osteocytes $\sim$ between 10 and $15 \mu$ in size were located in bone lacunas, had polygonal or oval shapes, and short processes (-Fig. 4).

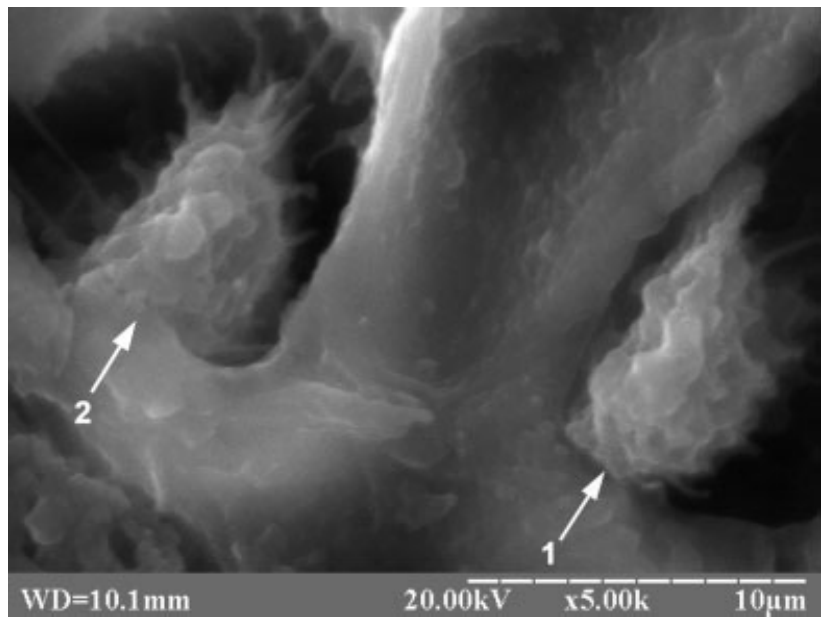

Fig. 4 The area of the femoral defect of the rat on the $15^{\text {th }}$ day after the implantation of Guidor easy-graft Crystal. Primary osteoblast (1) and osteocyte (2) in the lacunas of reticular fibrous bone tissue, which is formed on the surface of the osteoplastic material. Electronic scanning image. 5000x magnification.
In the inter-ravine spaces of the bone tissue, there were fragments of calcium phosphate materials and connective tissue of the regenerate, which in animals of the first group occupied $25.48 \pm 1.4 \%$ and $19.06 \pm 1.13 \%$, respectively, and in animals of the second group occupied $39.23 \pm 1.45 \%$ and $37.85 \pm 1.52 \%$ of the entire defect area, respectively $(p<0.05)$. It should also be noted that there were no signs of inflammation in the implantation site of Collapan and of Guidor easy-graft Crystal, and the maternal bone adjacent to the defect site was characterized by the presence of bone lacunae with typical osteocytes in its composition.

On the $30^{\text {th }}$ day of the experiment in the area of implantation of Collapan and Guidor easy-graft Crystal there was found bone tissue, which had coarse-fiber and lamellar structure. The bone lacunas contained osteoblasts and osteocytes, which had a flattened or polygonal shape, a complex surface relief, short processes, and a size of 15 microns (-Fig. 5).

In addition to bone tissue in the defect area of the animals of the $2^{\text {nd }}$ group, small fragments and solid granules of Guidor easy-graft Crystal were detected, and in the site of implantation of Collapan, only small fragments of a biocomposite material were detected. There were also places of direct contact of bone tissue with calcium phosphate materials, as well as places in which thin layers of connective tissue were located between them. Compared with the 15th day of the experiment in the area of the defect of animals of the first and second groups, the amount of the bone tissue of the regenerate $(69.16 \pm 2.9 \%$ and $34.25 \pm 1.64 \%)$ increased by $24.7 \%(p<0.05)$ and $49.43 \%(p<0.05)$, and the amount of biomaterial residues ( $16.39 \pm 0.93 \%$ and $35.23 \pm 1.49 \%$ ), on the contrary, decreased by $35.67 \%(p<0.05)$ and $10.19 \%$ $(p>0.05)$. The intertrabeular space of the reticular fibrous bone tissue was filled with fragments of biocomposite materials (Collapan, Guidor easy-graft Crystal) and with connective tissue of the regenerate ( - Fig. 6 ).

The connective tissue of the regenerate, in the composition of which fibroblasts were well traced, collagen fibers

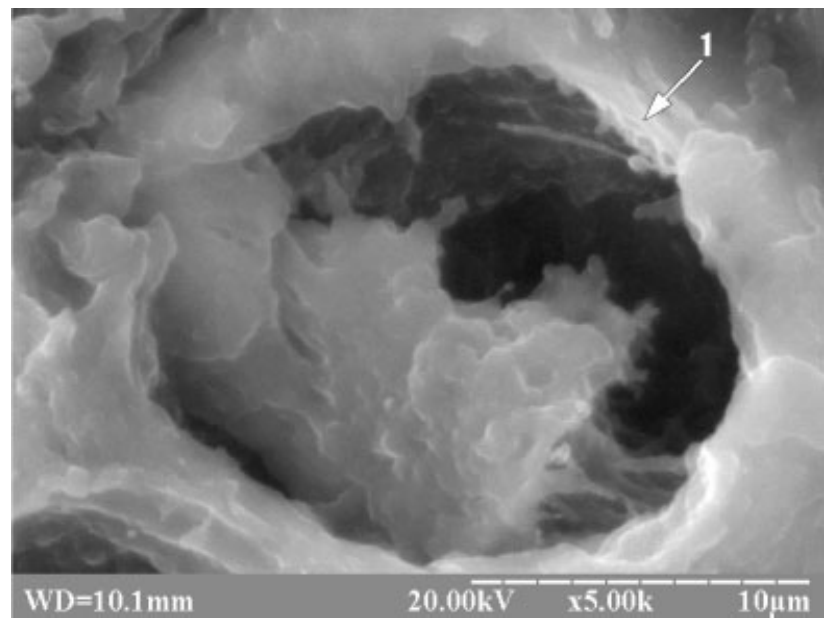

Fig. 5 The area femoral defect of the rat on the $30^{\text {th }}$ day after the implantation of Collapan. Primary osteoblast (1) in the lacuna of the bone tissue of regenerate, which is formed on the surface of the osteoplastic material. Electronic scanning image. 5000x magnification. 


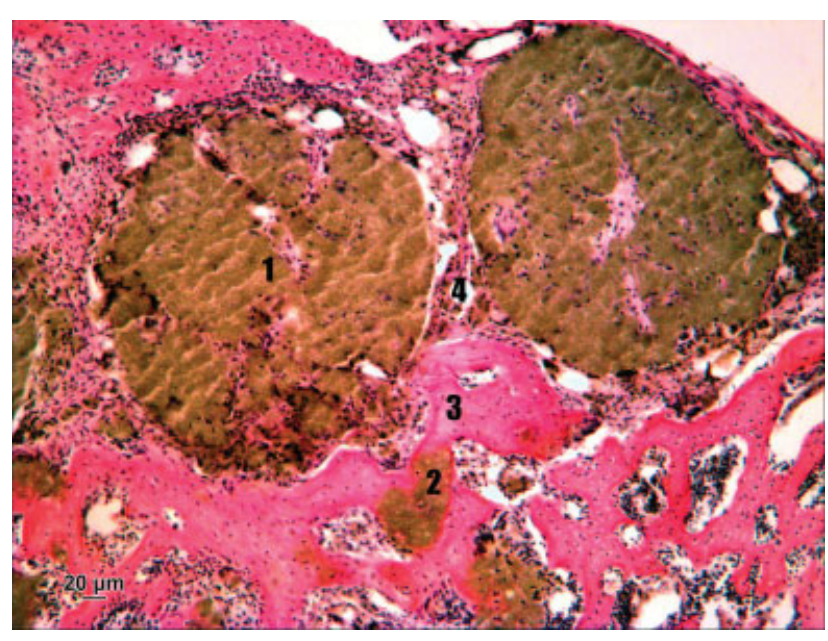

Fig. 6 The area of the femoral defect of the rat on the $30^{\text {th }}$ day after the implantation of Guidor easy-graft Crystal (hematoxylin and eosin). Solid granules of Guidor easy-graft Crystal (1) and their small fragments (2) integrated into the bone (3) and connective (4) tissues of the regenerate. bar $=20 \mu \mathrm{m}$.

and vessels occupied $16.39 \pm 0.93 \%$ in animals of the first group, and in animals of the second group $-30.51 \pm 1.63 \%$ of the entire defect area $(p<0.05)$, which in turn was $24.18 \%$ $(p<0.05)$ and $19.39 \%(p<0.05)$ less compared to the previous observation period. It should also be noted that, as in the previous period of observation in the area of implantation of Collapan and Guidor easy-graft Crystal there were no signs of inflammation, osteogenic cells showed a high tropicity to the studied biomaterials, and the maternal bone adjacent to the site of the defect was characterized by the presence of lacunae with typical osteocytes.

\section{Discussion}

The study conducted using light and scanning electron microscopy showed that the dynamics of healing of the defect of the femoral shaft had both common features and differences depending on the calcium phosphate material implanted in its cavity. Common features include the fact that the biocomposite materials Collapan and Guidor easygraft Crystal during the whole period of the experiment demonstrated a high biocompatibility, as evidenced by the absence of inflammation, necrosis, and necrobiosis osteocytes in the maternal bones in the place of their implantation. These results are consistent with the data of most researchers. ${ }^{4,8,15,17-19,22-24}$ In addition, the microscopic examination revealed a high topicity of osteogenic cells to the calcium phosphate materials Collapan and Guidor easygraft Crystal. At the same time, Köhli also observed the penetration of osteogenic cells into the calcium phosphate material Guidor easy-graft Crystal at the $4^{\text {th }}$ and $16^{\text {th }}$ weeks after its implantation into bone defects in rabbit skulls. ${ }^{4}$ However, Berchenko et al did not indicate the topicity of cellular elements to the granules of the biocomposite material Collapan on the $30^{\text {th }}, 60^{\text {th }}$ and $90^{\text {th }}$ days after its implantation into defects in the epiphyses of tibias of rats. But the authors reported osteoblasts in the bone tissue, which were formed directly on the surface of Collapan, and the absence of fibroblasts on the surface of the osteoplastic material. ${ }^{18}$ In our study, at all periods of observation, osteogenic cells were located and formed foci of fibrogenesis and osteogenesis, both on the outer surface and inside the biocomposite materials Collapan and Guidor easy-graft Crystal. It should be noted that the established fact is also the proof of the good integration of tissue-specific structures of the regenerate with biocomposite materials and the manifestation of their osteoconductive properties. This is connected with the fact that one of the definitions of osteoconduction is the ability of osteogenic cells to use osteoplastic material as a platform for attachment and generation on the surface and in its cavities of the tissue-specific structures of the regenerate. ${ }^{14}$

Another common feature of the materials Collapan and Guidor easy-graft Crystal was found with the help of light and raster electron microscopy. Thus, in the area of their implantation, at all periods of observation, only signs of desmal osteogenesis were revealed, as evidenced by the formations in the cavity of the defect of the bone and connective tissues of the regenerate. At the same time, in the defect cavity, there were places on the surface of Collapan and Guidor easy-graft Crystal where only bone tissue was formed and matured, but a part of the osteoplastic materials was integrated into the connective tissue of the regenerate. It was also observed a direct integration of small residues of Guidor easy-graft Crystal and of Collapan with the bone tissue of the regenerate, and between their large fragments and the bone tissue of the regenerate there remained a thin layer of connective tissue. Consequently, the studied osteoplastic materials (Collapan and Guidor easygraft Crystal) were well integrated with tissue-specific regenerate structures - both with bone and connective tissue. At this stage, we want to focus especially on the drug Collapan, which most researchers report that only bone tissue of the regenerate was formed on its surface, and that connective tissue was not observed on the surface of the biocomposite material. ${ }^{16,18,19}$ We have not found this information about the Guidor easygraft Crystal in the literature. According to the results of our study, we can say that not only bone, but also connective tissue of the regenerate is formed on the surface of the calcium phosphate material Collapan implanted into the femoral shaft defect, and the implant fragments are well integrated into their structures.

The present study also found that the bone and connective tissues of the regenerate, which were formed directly on the surface and inside the biocomposite materials, separated them into separate fragments and integrated them into their structures. It should be noted that, during the entire period of the experiment, Collapan was divided into the smallest fragments and integrated into the tissue-specific structures of the regenerate. Its consistency in comparison with Guidor easy-graft Crystal granules is soft, which, in our opinion, is an explanation for its division into small fragments already on the $15^{\text {th }}$ day of the experiment. In turn, Guidor easy-graft Crystal was also divided into smaller fragments. However, in comparison with Collapan, this speed was much slower, because during the entire period of the experiment, in the 
area of the defect of compact bone tissue, in the vastmajority, the solid, round shape of granules of the biocomposite material Guidor easy-graft Crystal was preserved.

We would also like to note that one of the most important properties of calcium-phosphate osteoplastic materials is their ability to resorption and replacement by tissue-specific regenerate structures. The literature presents works on the effect of biocomposite materials Collapan and Guidor easy-graft Crystal on the healing of bone defects. However, these studies were performed on the bones of the skull and on trabecular bones. For example, Schmidlin et al observed in their study that the frontal and parietal bones defects of rabbits had a tumor of the regenerate bone tissue directly on the surface of the Guidor easy-graft Crystal granules. However, the percentage of bone tissue at the $4^{\text {th }}$ and $16^{\text {th }}$ weeks after the Guidor easy-graft Crystal implantation was relatively small $(20.16 \pm 5.27 \%$ and $22.40 \pm 5.54 \%$, respectively) and, most importantly, between them there was no statistically significant difference. ${ }^{12}$ According to the authors, one of the factors that could affect this is the low rate of resorption of osteoplastic material. Slow biodegradation of the Biphase material according to Lindgren C. and co-authors may be due to the fact that only $\beta$-tricalcium phosphate phase of the drug is subjected to resorption, while hydroxylapatite does not dissolve for a long time and retains the area occupied by it. In our experiment, the Guidor easygraft Crystal was also subjected to resorption very slowly, as evidenced by an unreliable difference in its remains in the implantation site on the 15 th $(39.23 \pm 1.45 \%)$ and 30th $(35.23 \pm 1.49 \%)$ day of observation. However, using the morphometric method, we also established the dynamics of changes in the quantitative parameters of the implant, bone and connective tissue of the regenerate in the bone defect area. Analyzing the morphometric parameters in animals of both experimental groups, it should be noted that both on the 15th and 30th days of the experiment, the predominance of the rate of resorption of the biomaterial (of 35.04\% [ $p<0.05$ ], and of $53.47 \%[p<0.05]$, respectively) and the formation of the bone tissue of the regenerate $(58.67 \%[p<0.05]$, and $50.47 \%$ [ $p<0.05]$, respectively) was in the phase of implantation of Collapan, and the amount of connective tissue in the area of implantation of Collapan $(19.06 \pm 1.13 \%$, and $14.45 \pm 1.1 \%$, respectively) was almost two times less $(p<0.05)$ than in the area of implantation of Guidor easy-graft Crystal (37.85 $\pm 1.52 \%$, and $30.51 \pm 1.63 \%$, respectively).

\section{Conclusion}

Thus, the examined biocomposite materials in the area of the defect of compact bone tissue exhibit a high biocompatibility, osteoconductive properties and good integration with the tissues of the regenerate. However, the biocomposite material Collapan is subjected much faster to resorption and replacement by the bone tissue of regenerate, and Guidor easy-graft Crystal ensures the stability of the volume of the defect of compact bone tissue due to good integration with tissuespecific structures of the regenerate and to the absence of reliable signs of resorption throughout the duration of the experiment.
Conflicts of Interests

The author has no conflicts of interests to declare.

\section{References}

1 Pankratov AS, Lekishvili MV, Kopetsky IS. Bone grafting in dentistry and maxillofacial surgery. Osteoplastic materials: A Guide for Physicians. Moscow: BINOM; 2011

2 Cohen C, Bernard R. Endodontics. Saint Petersburg: Interline; 2000

3 Daculsi G, Laboux O, Malard O, Weiss P. Current state of the art of biphasic calcium phosphate bioceramics. J Mater Sci Mater Med 2003;14(03):195-200

4 Köhli M. Evaluation of moldable in situ hardening bone graft substitute in an animal model. Implants extra international magazine of oral implantology. Bone regeneration. Special Edition Degradable Solutions AG 2012;01:5-34

5 Jensen SS, Bornstein MM, Dard M, Bosshardt DD, Buser D. Comparative study of biphasic calcium phosphates with different $\mathrm{HA} / \mathrm{TCP}$ ratios in mandibular bone defects. A long-term histomorphometric study in minipigs. J Biomed Mater Res B Appl Biomater 2009;90(01):171-181

6 LeGeros RZ, Lin S, Rohanizadeh R, Mijares D, LeGeros JP. Biphasic calcium phosphate bioceramics: preparation, properties and applications. J Mater Sci Mater Med 2003;14(03):201-209

7 Malard O, Guicheux J, Bouler JM, et al. Calcium phosphate scaffold and bone marrow for bone reconstruction in irradiated area: a dog study. Bone 2005;36(02):323-330

8 Lan Levengood SK, Polak SJ, Wheeler MB, et al. Multiscale osteointegration as a new paradigm for the design of calcium phosphate scaffolds for bone regeneration. Biomaterials 2010;31 (13):3552-3563

9 Zafiropoulos GG, Hoffmann O, Kasaj A, Willershausen B, Weiss O, van Dyke TE. Treatment of intrabony defects using guided tissue regeneration and autogenous spongiosa alone or combined with hydroxyapatite/beta-tricalcium phosphate bone substitute or bovine-derived xeno-graft. J Periodontol 2007;78(11):2216-2225

10 Dorozhkin SV. Calcium orthophosphate-containing biocomposites and hybrid biomaterials for biomedical applications. J Funct Biomater 2015;6(03):708-832

11 Lindgren C, Hallman M, Sennerby L, Sammons R. Back-scattered electron imaging and elemental analysis of retrieved bone tissue following sinus augmentation with deproteinized bovine bone or biphasic calcium phosphate. Clin Oral Implants Res 2010;21(09): 924-930

12 Schmidlin PR, Nicholls F, Kruse A, Zwahlen RA, Weber FE. Evaluation of moldable, in situ hardening calcium phosphate bone graft substitutes. Clin Oral Implants Res 2013;24(02):149-157

13 Tsuchiya A, Sotome S, Asou Y, et al. Effects of pore size and implant volume of porous hydroxyapatite/collagen $(\mathrm{HAp} / \mathrm{Col})$ on bone formation in a rabbit bone defect model. J Med Dent Sci 2008;55(01):91-99

14 Jenkins MJ. Polymers in biology and medicine. Moscow. Sci World 2011

15 Germanov VG, Kovalersky GM, Cherkashena ZA, Semenov VA. Osteoplastic surgery: From bone transplant to the modern biocomposite materials. Medical Assistance Available 2006;04:16-19

16 Iordanishvili AK, Gololobov VG, Baschenko YV, Sakharov NV. Collapan \$a modern optimizer of reparative osteogenesis. Ambulatory surgery. Hospital Replacing Technologies 2002;2:6-8

17 Ruffieux K, Kohli M. Build-up of bone tissue. Materials research and clinical application instructions easy-graft ${ }^{\circledR}$ materials and easy-graft®CRYSTAL. Kiev: Company “Stam”; 2011

18 Berchenko GN, Kesyan GA, Urazgildeev RZ, Arsenyev IG, Mikelaishvili DS. Comparative experimental morphological study of the effect of some calcium phosphate materials used in trauma and orthopedic practice to activate reparative osteogenesis. Bulletin of the East Siberian Scientific Center. Siberian Branch of Russian Academy of Medical Sciences 2006;4:327-333 
19 Protsenko AI, Nikuradze VK. Collap An in surgery of injuries and diseases of the cervical spine. Moscow: Typography HT-print; 2013

20 Yuehuei HA, Kylie LM. Handbook of Histology Methods for Bone and Cartilage. Totowa, New Jersey: Humana Press; 2003

21 Grigorian AS, Toporkova AK. Problems of integration of implants in bone tissue (theoretical aspects). Moscow: Technosphere; 2007

22 Barer GM, Vavilov TP, Tumanov AS. The use of the biocomposite drug "CollapAn" containing various antibacterial inclusions on the surgical stage of complex treatment of periodontitis. Kafedra 2004;10:45-49

23 Snetkov AI, Batrak SY, Frantov AR, Avakian AM. Applications of implant "CollapAn" in the clinic of pediatric bone pathology. Biomaterials 2006;5:2-4

24 Glaser R. Rehabilitation mit 3D Planung und Kieferkammerhalt. Zahnarzt 2009;04:29-31

25 Semenyak SA, Rublenko MV, Dudka VB. Clinical and morphologic characteristics using of osteotropic materials to replace bone defects in animals. Vet Med 2015;100:157-161 